\title{
Com a palavra, o visitante: avaliação e mensuração de resultados do programa visite o Congresso
}

\section{The visitor's opinion: evaluation and results measurement of the Visit the Congress Program}

\section{Resumo}

O Visite o Congresso é um dos programas de relações públicas das instituições do Legislativo federal. O presente artigo identifica e descreve informações sobre a qualidade do Programa Visite o Congresso por meio da análise de conteúdo das mensagens registradas pelos visitantes no livro Palavra do Visitante. Essa análise aponta que o Programa Visite o Congresso é visto pela maioria dos participantes como didático e importante, aumentando a compreensão a respeito do Poder Legislativo. Além disso, o artigo descreve o tratamento dado pelo Senado Federal e pela Câmara dos Deputados às manifestações dos visitantes. Nesse sentido, é percebida a oportunidade de estreitamento do diálogo entre essas instituições legislativas e seus públicos. Percebe-se, à luz de revisões bibliográficas sobre os temas relações públicas, comunicação pública, e avaliação e mensuração de resultados, que o Palavra do Visitante pode ser útil aos gestores do Visite o Congresso, para que aprimorem o relacionamento com os públicos do Programa.

Palavras-chave: Comunicação pública. Relações públicas. Programa de visitas. Análise de conteúdo. Mensuração de resultados.

\begin{abstract}
The Visit the Congress is one of the public relations programs of the Brazilian Federal legislative institutions. The present article identifies and describes information about the quality of the Visit the Congress through the content analysis of the messages registered by citizens in the Visitors Book. This research points out that the Visit the Congress program is seen by most participants as didactic and important, expanding the comprehension about the Legislative Branch. Moreover, this article describes the treatment given by the Federal Senate and the Chamber of Deputies to the visitor's written opinions. In this manner, a closer dialog between the legislative institutions and their publics is perceived. It is also apprehended, in the light of a bibliographic review on the themes public relations, public communication, evaluation and results measurement, that the Visitors Book can be useful to the managers of the Visit the Congress, in such a way that they may improve the relationship with the program's publics.
\end{abstract}

Keywords: Public communication. Public relations. Visitation program. Content analysis. Results measurement. 


\section{Introdução}

O Visite o Congresso é um dos programas de relações públicas das instituições que compõem o Poder Legislativo brasileiro: a Câmara dos Deputados e o Senado Federal. O Programa possibilita o acesso sistemático de cidadãos a alguns dos principais espaços das duas casas legislativas.

Até 2010, não havia uma forma consistente de avaliar as impressões dos visitantes sobre o Programa, a não ser pelas reações percebidas imediatamente pelos próprios mediadores ao final de cada visita. Constatando essa necessidade, a Secretaria de Relações Públicas do Senado Federal e a Coordenação de Relações Públicas da Câmara dos Deputados implantaram uma ferramenta de feedback espontâneo, que se denominou Palavra do Visitante. Desde então, o livro tem sido utilizado pelos visitantes, reunindo significativa quantidade de dados.

A partir desses dados, que informações podem ser extraídas sobre a qualidade do programa Visite o Congresso e quais as percepções dos cidadãos durante a visita mediada às dependências do Palácio do Congresso Nacional?

O objetivo deste artigo é responder essas questões, considerando que a comunicação face a face proporcionada pela visitação é uma das formas mais tangíveis de contato entre o Parlamento e os cidadãos.

A relevância do presente trabalho está em oferecer aos gestores do Programa subsídios para compreender melhor o que pensam seus públicos de interesse e, dessa maneira, ir ao encontro dessas expectativas, melhorando a qualidade do serviço prestado. Esta pesquisa valoriza as opiniões dos visitantes, dando-lhes a oportunidade de serem co-autores do serviço de visitação prestado pelo Congresso Nacional. Outras instituições públicas que oferecem programas de visitas poderão avaliar a aplicabilidade desse método, de natureza de mensuração de resultados, em seus próprios contextos. Para a academia, o estudo pode servir como exemplo de situação real de relacionamento entre instituições públicas e seus públicos e para aprofundar a discussão sobre pressupostos teóricos de relações públicas e mensuração de resultados.

Ao final deste estudo, apontam-se algumas condições para bons resultados de relações públicas no contexto das organizações públicas, à luz de revisão bibliográfica sobre relações públicas, comunicação pública, avaliação e mensuração de resultados.

\section{Material e métodos}

Para a contextualização do tema, uma pesquisa bibliográfica sobre comunicação pública, relações públicas e mensuração de resultados foi realizada. É descrito também um panorama sobre os sistemas de comunicação da Câmara e do Senado, as Relações Públicas de ambas as Casas e o Programa de Visitas do Congresso Nacional como ação de relações públicas, com base nos arquivos eletrônicos da Secretaria de Comunicação Social do Senado Federal.

Para a análise do conteúdo, foram tabulados, em planilhas Excel, 1.028 registros de visitantes, classificados em quatro categorias. Cada registro contém uma ou mais manifestações. O número total de manifestações analisadas foi de 1.218.

Esses registros, feitos no período entre abril de 2010 e abril de 2011, estão localizados nos três primeiros livros do Palavra do Visitante. Os livros estão armazenados no arquivo da Secretaria de Relações Públicas do Senado Federal. Cada livro contém 400 páginas numeradas.

\section{Desenvolvimento}

\subsection{O papel das relações públicas no contexto da comunicação pública}

A expressão comunicação pública tem sido utilizada ao longo do tempo e ao redor do mundo em diferentes contextos, com múltiplos significados.

No Brasil, Brandão (2009, p. 9) identifica "um ponto comum de entendimento que é aquele que diz respeito a um processo comunicativo que se instaura entre $o$ Estado, o governo e a sociedade com o objetivo de informar para a construção da cidadania”.

Sem citar especificamente o termo comunicação pública, Torquato (2011, p. 128) destaca uma lista de funções da comunicação na administração pública, entre as quais as que estabelecem a comunicação como base de cidadania, como forma de democratização do poder e de orientação aos cidadãos. 
Oliveira (2011, p. 80) pontua que "as instituições públicas, privadas e do terceiro setor existem para servir ao cidadão e não o inverso". Assim, defende que "o cidadão é o sujeito, e não o objeto. O cidadão é o elemento central, não o periférico". Nessa perspectiva, o status do cidadão passa de simples receptor a interlocutor, de espectador a ator social.

O protagonismo do cidadão na construção da própria cidadania pressupõe como componente indispensável, segundo Márcia Duarte (2009, p. 101), a sua participação.

Matos (2009, p. 53), ao relacionar esfera pública e comunicação pública, estabelece como base de discussão:

[...] elaboração de uma cultura (cívica e comunicacional) do que seja público e do valor deste público. Uma cultura que capacite os agentes a instituírem-se como comunicadores públicos na esfera pública. Mesmo uma pequena empresa e um indivíduo com baixa escolaridade podem ser participantes da esfera pública, desde que se sintam imbuídos de sua importância e do valor de sua participação.

Essa posição coincide com um tipo de perspectiva de comunicação pública que, para Jorge Duarte (2009, p. 61), coloca o cidadão no centro do processo, "não apenas por meio da garantia do direito à informação e à expressão, mas também do diálogo, do respeito a suas características e necessidades, do estímulo à participação ativa, racional e corresponsável". O autor reconhece que essa ideia é, por vezes, considerada ingênua e até utópica por aqueles "para quem a comunicação, ainda e infelizmente, é considerada apenas um tipo de concessão paternalista, de angariar apoio, instrumento de persuasão, manipulação, sedução, para disputa ou manutenção do poder [...]."

Pierre Zémor (2009, p. 220), fundador da Associação francesa Communication Publique, vincula a comunicação pública no que compete às instituições não apenas à disponibilização de dados e informações. A recepção, a escuta e o diálogo são evidenciados pelo autor como atitudes intrínsecas ao serviço público.

O diálogo entre a instituição e os cidadãos/usuários é definido por Zémor (2009, p. 222) como via essencial de avaliação e coprodução dos serviços públicos.

Ainda segundo o autor francês (2009, p. 230):

A comunicação pode propor os antídotos para banir as ideias preconcebidas e os jargões, para desenvolver a escuta social, multiplicar reportagens, operações de portas abertas - todas iniciativas que despertam o interesse imediato dos ci- dadãos e tornam mais acessíveis as instituições políticas, judiciárias e administrativas.

Diante desse contexto, as relações públicas têm importante contribuição a oferecer, desde que exerçam seu papel estratégico de criar e manter relacionamentos mutuamente benéficos e sejam vistas, dentro da perspectiva de Grunig (2009, p. 24), "como uma função de vinculação com os stakeholders, e não como um conjunto de atividades para a transmissão de mensagens, elaboradas para proteger a organização dos seus públicos".

O potencial máximo de resultados organizacionais que podem ser alcançados por meio das relações públicas, porém, parece intrinsecamente ligado à posição ocupada pelos profissionais da área. Grunig (2009, p. 41) afirma que:

As relações públicas muito possivelmente contribuem para a eficácia quando o executivo de relações públicas é membro da coalizão dominante, participa do estabelecimento dos objetivos da organização e auxilia na identificação dos públicos externos mais estratégicos.

É de Grunig (2009, p. 56) a Teoria da Excelência em relações públicas, que estabelece como pressuposto a busca permanente da simetria de mão dupla no sistema organização-públicos. Dentro dessa perspectiva, o equilíbrio de interesses da organização com seus públicos tem como ponto de partida a pesquisa e se utiliza da comunicação para administrar conflitos e cultivar relacionamentos de qualidade com públicos estratégicos.

Para instituições privadas, o resultado do esforço de construção e manutenção de relacionamentos reverte em reconciliação dos objetivos organizacionais com as expectativas dos stakeholders, contribuindo para a eficácia organizacional. Para órgãos públicos, o alvo é estabelecer um terreno comum que favoreça o diálogo e a participação em nome do interesse público. Grunig (2009, p. 91) propõe terminologia específica para descrever os resultados a serem alcançados pelas relações públicas simétricas de mão-dupla, adaptadas aqui no contexto das instituições públicas:

a) Percepção mútua: a organização pública e os cidadãos percebem o efeito que exercem um sobre o outro;

b) Exatidão: o cidadão e a instituição entendem e podem repetir o que o outro disse;

c) Compreensão: ambos têm conhecimento e informações semelhantes sobre um 
problema, assunto emergente ou papel institucional da organização;

d) Concordância: pelo diálogo e participação, chega-se a um acordo sobre os rumos a serem tomados;

e) Comportamento simbiótico: instituição e cidadãos comportam-se de forma a atender ao interesse público.

Finalmente, para alcançar resultados significativos em comunicação pública, dentre as variadas modalidades de ações de relações públicas, destaca-se um processo elementar de comunicação, sem o intermédio de qualquer veículo de massa: a comunicação direta. Segundo Jorge Duarte (2009, p. 66):

Opção relevante, ainda costumeiramente su-
bestimada nos planejamentos, é a comunica-
ção direta. Possuidora de alta eficiência por
ajustar de maneira imediata a comunicação às
características dos interlocutores, refere-se ao
contato personalizado, geralmente do tipo face
a face, que inclui (entre outras) atendimento,
[...] sua característica principal é permitir fa-
cilidade de interação, troca de informações,
influência mútua e maior capacidade de com-
preensão.

Dessa forma, a comunicação direta no contexto das instituições públicas e governamentais pode potencializar a geração de resultados benéficos para o público e para as próprias organizações.

\subsubsection{Mensuração de resultados em relações públicas}

Lopes (2009, p. 395) estabelece uma distinção entre os processos de mensuração e de avaliação. O primeiro está voltado para a demonstração de resultados; o segundo é uma etapa do planejamento que acompanha e ajusta a implantação de um projeto.

Feita essa diferenciação, a autora mapeia alguns modelos de avaliação e de mensuração em comunicação e relações públicas propostos e/ou empregados em outros países: o Modelo PII - preparação, implementação e impacto; a Régua da efetividade; o Modelo de curta duração; o Modelo contínuo; o Modelo de duas fases; a Variação compensatória; e os Indicadores da qualidade dos relacionamentos entre uma organização e seus públicos.

Galerani (2006, p. 72), por meio de extensa pesquisa bibliográfica, identifica e descreve esses sete modelos, apresentados a seguir.
O Modelo PII - preparação, implementação e impacto -, desenvolvido por Scott Cutlip, Allen Center e Glen Broom, estabelece três fases para avaliar se as expectativas da organização foram atendidas com um programa ou ação de comunicação. A fase de preparação é o momento de elaborar o plano de comunicação e estabelecer objetivos. $\mathrm{Na}$ implantação, monitoram-se o esforço e a estratégia empregada para a execução do plano e, por meio de pesquisas de receptividade, avalia-se a adequação dos projetos e ações quanto ao público a ser atingido, aos códigos das mensagens, aos padrões de desempenho e às situações não previstas. Na terceira fase, verificamse o retorno e os resultados alcançados, a partir de uma pesquisa que compara os resultados com os objetivos traçados inicialmente.

O Modelo da régua da efetividade, de Walter Lindenmann, propõe duas etapas essenciais para a avaliação em relações públicas: em primeiro lugar, definem-se os objetivos para a comunicação e, depois, se decide sobre o nível em que se deseja medir a efetividade da ação ou programa. No nível básico, medem-se quantidade e qualidade de produtos de comunicação. No intermediário, avaliam-se as impressões, a percepção e a retenção do público diante da mensagem. A mudança de comportamentos, atitudes e opiniões decorrentes da comunicação são o terceiro e mais profundo nível de avaliação.

O britânico Tom Watson é o autor do Modelo de curta duração e do Modelo contínuo. O primeiro é voltado para ações de curto prazo, como campanhas de mídia e outras atividades que buscam resultados imediatos. $\mathrm{O}$ alcance da comunicação é medido pela análise da mídia ou resposta às vendas, ou mesmo por meio de pesquisa quantitativa telefônica com o público-alvo. O modelo contínuo é elaborado para ações de longo prazo, cujo monitoramento deve considerar os efeitos da comunicação quanto ao comportamento e às atitudes desejadas no planejamento.

Medir o impacto econômico da comunicação organizacional é a proposta do Modelo de duas fases, desenvolvido por Yunwook Kim. Nesse modelo, avaliam-se, no âmbito da organização, o impacto dos investimentos em comunicação na reputação e os efeitos da reputação no lucro da empresa.

A Variação compensatória, ou Modelo da compensação variável, foi idealizada pelo norte-americano 
Willian Ehling e também busca calcular o valor econômico das ações de comunicação organizacional. Esse valor deriva da conversão de efeitos não monetários em monetários, a partir de uma escala de graus que variam entre mínimo e máximo conflito e mínima e máxima cooperação entre uma empresa e seus públicos. Quanto maior o conflito e menor a cooperação, maior o prejuízo monetário. Quanto maior a cooperação e menor o conflito, maior é o resultado financeiro da ação comunicacional.

Galerani (2006, p. 90) explica ainda as diretrizes dos seis Indicadores da qualidade dos relacionamentos entre uma organização e seus públicos, propostas por Linda Childers Hon e James Grunig. Consiste em metodologia que determina a qualidade do relacionamento tanto sob o ponto de vista da empresa quanto do público, a partir da aplicação de questionários sobre seis aspectos: confiança, mútuo controle, comprometimento, satisfação, relacionamento de troca e relacionamento comunal.

Entre as iniciativas brasileiras de modelos de avaliação em comunicação e relações públicas, Lopes (2009, p. 403) cita o Índice de Desenvolvimento Institucional, elaborado pela LVBA Comunicação, que tem como base o balanced score card e se vale de pesquisas para monitorar as ações comunicacionais a fim de não permitir que se descolem do planejamento estratégico.

O balanced score card é técnica desenvolvida por Kaplan e Norton que integra os indicadores de desempenho existentes em uma empresa, estabelecendo objetivos de qualidade para cada função e nível da organização, com metas claramente definidas. Busca-se com isso dar tangibilidade à missão e à estratégia da organização considerando quatro perspectivas: a financeira, a dos clientes, dos processos internos e de aprendizado e crescimento (SANTOS, 2008).

Além dos modelos citados, a pesquisa de opinião destaca-se como um dos meios mais comuns de medir resultados em relações públicas. Entretanto, a dificuldade em se aplicar questionários de opinião na quantidade suficiente para atender ao rigor estatístico, ou seja, com margem de erro reduzida, por vezes, impede o uso desse instrumento.

Outras formas de medição podem ser úteis quando não há meios ou recursos para a aplicação de pesquisas. Uma delas é a análise de conteúdo. Segundo o Dicionário de mensuração e pesquisa em relações públicas e comunicação organizacional (STACKS, 2007, p. 14), análise de conteúdo é:

Metodologia de pesquisa informal (e uma ferramenta de medida) que sistematicamente rastreia mensagens (escritas, faladas ou em audiovisual) e as traduz em formas quantificáveis utilizando uma abordagem sistemática, que define categorias de mensagens por meio de unidades de análise específicas; a ação de dividir o conteúdo das mensagens em componentes prédeterminados (categorias) de modo a formar um julgamento capaz de ser mensurado.

Possivelmente, um dos desafios desse tipo de abordagem é encontrar classes de mensagens que sejam suficientemente abrangentes, a ponto de agrupar dados em quantidades significativas para as análises. Por outro lado, há que se considerar que mensagens de difícil classificação, que não se encaixam nas categorias definidas, têm o potencial de revelar informações importantes que podem acabar sendo desprezadas se não houver atenção do observador.

\subsection{Mecanismos de interatividade com os públicos: desafio dos sistemas de comunicação do legislativo federal}

Os primeiros estudos e planejamento de relações públicas do Senado datam do final da década de 1950. Entretanto, foi a partir de meados da década de 1990 que as estruturas de comunicação existentes atualmente nas duas Casas legislativas foram criadas e/ou desenvolvidas.

Além da expansão das áreas de cobertura dos veículos de comunicação de massa (TV Senado e TV Câmara, Rádio Senado e Rádio Câmara), no decorrer da primeira década do Século XXI, os portais eletrônicos das duas Casas legislativas foram aperfeiçoados e a quantidade de conteúdos produzidos para a internet multiplicada diversas vezes. Ao mesmo tempo, novos programas e projetos de relações públicas e divulgação surgiram e se estabeleceram. Paralelamente, tanto a Comunicação da Câmara quanto a do Senado se engajaram em maior ou menor intensidade a atividades de planejamento global de objetivos e metas, bem como de descrição e sistematização de rotinas e tarefas e de discussões e/ou execução de reestruturações administrativas.

O desenvolvimento desses sistemas de comunicação pode significar uma vontade das duas instituições em divulgar suas ações legislativas e administrativas, bem como o desejo de serem compreendidas em suas missões constitucionais e dar mais transparência e visibilidade ao 
tríplice trabalho parlamentar de representação, legislação e fiscalização.

Entretanto, nos últimos anos, tem surgido, entre os profissionais de comunicação das duas casas, uma necessidade de receber e compreender as demandas de seus públicos. No artigo "Avanços e desafios do sistema de comunicação da Câmara dos Deputados" (BARROS et al., 2008, p. 44), os pesquisadores coletaram impressões de 30 servidores que trabalham na área de comunicação daquela instituição legislativa. Muitas das opiniões registradas apontam para a necessidade de ouvir e entender as demandas dos públicos-cidadãos:

\begin{abstract}
Do mesmo modo, os servidores da instituição apontam como um dos maiores desafios a urgente necessidade de identificar as principais demandas da sociedade e mapear, de forma segmentada, os principais públicos de interesse, a fim de direcionar os diferentes produtos e serviços oferecidos. Essa seria uma forma de conquistar maior legitimidade, com o devido reconhecimento dos públicos aos quais essa produção se destina.
\end{abstract}

Meneguello (2012, p. 13), ao estudar as percepções públicas sobre o Parlamento brasileiro nos últimos 50 anos conclui que:

Entre as razões dessa falta de confiança e descrédito, a percepção da ineficiência das instituições para articular e responder às demandas da sociedade e da presença de motivações meramente individuais para boa parte dos políticos concentra as principais críticas dos cidadãos.

Serviços de atendimento ao cidadão, como o Disque Câmara e o Alô Senado, são formas de suprir em parte a necessidade de ouvir o cidadão em suas demandas, interesses e opiniões.

O DataSenado (SENADO FEDERAL, 2012) é outra ferramenta que tem por objetivo "estreitar a comunicação entre o Senado Federal e as necessidades e anseios da sociedade". Além de realizar pesquisas de opinião com validade estatística, promove quinzenalmente enquetes pela internet, com a meta de sondar tendências e expectativas.

$\mathrm{Na}$ esfera do debate legislativo, novas ferramentas, como os sites e-democracia da Câmara dos Deputados e e-cidadania, do Senado Federal, buscam facilitar o acesso dos cidadão à proposição de ideias legislativas, permitem a participação de internautas em fóruns de discussão e apresentam links para outras formas de contato com as instituições parlamentares.
O Senado e a Câmara também estão presentes em redes sociais como Twitter e Facebook, cujos perfis gradualmente vão adquirindo um caráter mais interativo, não apenas de divulgação de informações, especialmente no caso do@camaradeputados.

Indicadores de resultados ainda precisam ser definidos, a fim de mensurar a eficácia dessas ferramentas como meio de interação entre o Legislativo e os cidadãos.

Por fim, para cumprir a Lei de Acesso à Informação (Lei 12.527/2011), que entrou em vigor em maio de 2012, Senado e Câmara dispõem de balcões de atendimento presencial ao cidadão que quiser solicitar qualquer tipo de informação administrativa ou legislativa, devendo ser respondido dentro de prazos específicos.

\subsubsection{Setores de relações públicas no Congresso $\mathrm{Na}$ - cional}

No Senado Federal, a primeira iniciativa de relações públicas surge em 1959, com a designação de um servidor para estudar e planejar a criação de um serviço de relações públicas. Em 1972 (DUARTE, M., 2008, p. 322), foi criada a Secretaria de Divulgação e Relações Públicas, com a tarefa de "planejar, supervisionar, controlar e dirigir as atividades relacionadas aos processos de comunicação externa do Senado Federal."

Hoje, parte expressiva dos profissionais da Secretaria de Relações Públicas está envolvida com o planejamento e execução de eventos de diversas naturezas: sessões plenárias, lançamentos, seminários, palestras, aposições e os compromissos constitucionais: posse presidencial e de senadores eleitos.

Além disso, é realizado anualmente o Programa Senado Jovem Brasileiro, em duas etapas: o Concurso Nacional de Redação e Projeto Jovem Senador. O Programa busca promover a participação cidadã e o civismo entre jovens de 15 a 19 anos da rede pública de ensino, simulando o trabalho parlamentar. As sugestões dos jovens senadores podem inclusive tramitar como projetos de lei por meio da Comissão de Direitos Humanos e Legislação Participativa do Senado.

Outra frente de trabalho diz respeito ao planejamento, execução e/ou apoio às exposições, campanhas institucionais e ações de comunicação interna.

Em 2012, os profissionais da área de Assessoria de Imprensa foram instalados fisicamente nas dependências 
da Secretaria de Relações Públicas e respondem diretamente à diretora da área.

Finalmente, uma coordenação da Secretaria dedica-se aos assuntos relacionados à visitação institucional: programa de visitas, visitas especiais, intercâmbio com outras instituições que promovem visitas institucionais e o turismo cívico.

Embora não esteja mais subordinado à Secretaria de Relações Públicas, o Alô Senado, serviço de atendimento telefônico gratuito, foi concebido e estruturado como iniciativa de relações públicas.

Vale destacar ainda que alguns profissionais de relações públicas atuaram ou estão atuando em diversos setores estratégicos do Senado, como a Diretoria-Geral, a Primeira-Secretaria e o Interlegis, que é um programa desenvolvido pelo Senado Federal, em parceria com o Banco Interamericano de Desenvolvimento, que visa à modernização e à integração do Poder Legislativo nos seus níveis federal, estadual e municipal. Esses profissionais de relações públicas assessoram diretores na tomada de decisão, ou seja, embora não estejam dentro da caixa administrativa chamada Relações Públicas, ajudam a definir objetivos da organização.

Na Câmara dos Deputados, uma recente reestruturação administrativa agrupou os setores de Relações Públicas e Divulgação Institucional. A área é responsável pelo planejamento e execução dos mais variados eventos. Também organiza o Parlamento Jovem, que possibilita a estudantes vivenciarem o processo legislativo; e o Plenarinho, projeto pedagógico voltado para crianças e pré-adolescentes. Parte da equipe de relações públicas atua em ações de comunicação interna. Além disso, a área coordena o programa de visitas, o receptivo da Câmara, o Disque Câmara - serviço de atendimento 0800 - e realiza campanhas e outras ações de comunicação institucional.

\subsection{O programa visite o Congresso}

Desde a sua inauguração no ano de 1960, pela arquitetura singular e pelo que representa para o País, o Palácio do Congresso Nacional é vocacionado a atrair o interesse de visitantes.

Embora o Senado recebesse visitantes antes de 1995, aquele ano marca o início da contabilização e registro do número de pessoas que vinham ao Palácio com a finalidade de conhecer a sede onde as unidades da federação se fazem representar.

Até 2004, Senado e Câmara realizavam programas de visitas separadamente. A integração veio a partir de uma experiência bem sucedida, em razão de uma grande exposição realizada naquele ano no Salão Negro, espaço de recepção dos visitantes. A junção dos roteiros de visita da Câmara e do Senado diminuiu o tempo de espera e facilitou a compreensão do público sobre o bicameralismo do parlamento brasileiro. O número de visitantes aumentou significativamente desde então.

Durante a visita, o cidadão tem a oportunidade de obter informações sobre o processo legislativo, a composição do Parlamento, a função dos deputados e senadores, a história e sobre a arquitetura do Palácio do Congresso Nacional.

Há pelo menos três objetivos de relações públicas a serem alcançados pela atividade de visitação. O primeiro é aumentar a compreensão do público a respeito da composição, do funcionamento e das atribuições do Parlamento nacional, evidenciando ao cidadão o conceito da representação política e a importância da participação consciente no sistema democrático.

Outro objetivo é apresentar um conjunto arquitetônico que é patrimônio histórico e cultural e uma das principais atrações de turismo cívico do Brasil.

Finalmente, pela oportunidade de comunicação face a face que proporciona, o Visite o Congresso pretende ser uma forma tangível de o Parlamento se relacionar e se aproximar do público para o qual sua existência se justifica: os cidadãos brasileiros.

Tabela 1- número de visitantes ao Senado Federal

\begin{tabular}{c|c|}
\hline Ano & Número de Visitantes \\
\hline 1995 & 8455 \\
\hline 1996 & Sem registro \\
\hline 1997 & 46.635 \\
\hline 1998 & 33.762 \\
\hline 1999 & 44.172 \\
\hline 2000 & 57.694 \\
\hline 2001 & 55.391 \\
\hline 2002 & 54.450 \\
\hline 2003 & 59.148 \\
\hline 2004 & 136.274 \\
\hline
\end{tabular}




\begin{tabular}{c|c|}
\hline Ano & Número de Visitantes \\
\hline 2005 & 145.744 \\
\hline 2006 & 162.146 \\
\hline 2007 & 123.837 \\
\hline 2008 & 142.912 \\
\hline 2009 & 177.632 \\
\hline 2010 & 181.618 \\
\hline 2011 & 179.898 \\
\hline Total & 1.609 .768 \\
\hline
\end{tabular}

Fonte: Arquivo eletrônico da Secretaria de Relações Públicas do Senado Federal

Muitos visitantes chegam sem ter uma noção exata do que é a tripartição dos Poderes e perguntam pela Chefe do Executivo ou pelo Presidente do Supremo Tribunal Federal. Outros citam nomes de parlamentares atuais que, antes de se tornarem deputados ou senadores, já eram conhecidos pelo grande público por serem artistas ou desportistas. Finalmente, alguns comentam: "é aqui que o pessoal do $\mathrm{CQC}^{2}$ entrevista os deputados?!"

Outros expressam críticas ao desempenho dos parlamentares e questionam os plenários vazios em determinados horários de dias úteis. Com frequência, percebem-se a frustração e o ceticismo com relação à atuação parlamentar.

Os mediadores da visitação ao Congresso Nacional são constantemente instruídos a não emitirem opiniões pessoais, ideológicas ou político-partidárias. $\mathrm{O}$ roteiro da visita se concentra em informações de caráter institucional e busca esclarecer sobre a importância de instituições democráticas fortes (embora essa postura possa ser interpretada como uma ideologia). Conforme relatos dos próprios mediadores, à medida que os conteúdos vão sendo apresentados aos participantes, muda o tipo de pergunta e aumenta o interesse pelo processo legislativo, pela história brasileira e pelas formas de participação política do cidadão.

Muitas vezes os mediadores conseguem, no processo comunicacional da visitação, despertar a curiosidade do público pelo conteúdo cívico do programa. Nessas ocasiões, de forma empírica, é possível comprovar o poder da comunicação direta.

2 Sigla do nome do show humorístico da TV Band "Custe o que custar".
O livro Palavra do Visitante foi criado para que os visitantes pudessem registrar suas considerações sobre a qualidade do serviço de visitação, tendo em vista que a percepção que os mediadores têm dos visitantes é subjetiva.

Desde abril de 2010 até outubro de 2012, foram registradas mais de 3.300 manifestações espontâneas de cidadãos das mais diversas partes do País e do mundo. As críticas, elogios, dúvidas e sugestões não se concentram apenas no assunto Visita ao Congresso e, por essa razão, os registros dos visitantes também oferecem um panorama, ainda que incompleto e fragmentado, de impressões e opiniões das pessoas sobre o Congresso de um modo geral.

\subsubsection{Mapeamento dos públicos}

Para melhor analisar o conteúdo dos registros dos visitantes, faz-se necessário compreender os públicos com os quais se trabalha.

Entre as várias possibilidades de segmentação, que servem para facilitar o planejamento de ações, o método escolhido pela Secretaria de Relações Públicas do Senado para classificar os públicos do Programa Visite o Congresso é o proposto por França (2008), vide quadro 1, que classifica o tipo de relacionamento, os objetivos e as expectativas mútuas entre as organizações e seus públicos.

Essa não é a única maneira de classificar os públicos do Programa, mas é útil quando da adequação da visita monitorada a cada tipo de grupo.

Os cidadãos que resolvem se manifestar por escrito no livro Palavra do Visitante, oriundos de qualquer dos grupos enumerados, se distinguem dos demais, pois seu interesse se transforma em ação, ainda que de uma forma tão simples, como o registro de uma opinião. Por essa razão, este artigo debruçou-se em analisar o conteúdo desses registros, que poderão servir como subsídio para uma compreensão mais exata das expectativas dos públicos visitantes em relação ao Programa de Visitação e ao próprio Congresso Nacional.

\subsubsection{Pesquisa de dados e análise de conteúdo do Pa- lavra do Visitante}

A partir da análise do universo de visitantes ao Congresso Nacional, a Secretaria de Opinião Pública do Senado identificou dificuldades de aplicação de uma pesquisa de opinião. Para seguir o rigor estatístico com pouca margem de erro, a cada oito visitantes um teria que ser entrevistado. Por ano, a média de visitantes tem sido 
de 180 mil pessoas. Isso significa que pelo menos 22.500 pessoas teriam que preencher um formulário de pesquisa. O questionário não poderia ser aplicado, por exemplo, a todo um grupo de estudantes de determinada escola, devendo obedecer ao intervalo de um para cada oito visitantes.

Por esse motivo, a presente pesquisa optou por outra estratégia de mensuração denominada análise de conteúdo. Essa metodologia foi aplicada com mensagens registradas no livro Palavra do Visitante, no período entre 16 de abril de 2010 e 20 de abril de 2011, e será apresentada a seguir.

Cada registro, que corresponde a uma página do livro disponibilizado aos cidadãos que concluem a visita

Quadro 1- Público do Programa Visite o Congresso pelas dependências do Palácio do Congresso Nacional, pode conter uma ou mais manifestações. Foram analisados 1.028 registros, que totalizaram 1.218 manifestações, ao longo de um ano.

As manifestações foram classificadas em quatro categorias principais: ELOGIOS E AGRADECIMENTOS; SOLICITAÇÕES; CRÍTICAS; e SUGESTÕES. As mensagens em branco, as ilegíveis e os registros de presença foram agrupados e contabilizados, mas não entraram na análise de conteúdo.

Para facilitar a análise de conteúdo, foram destacadas entre 5 e 12 palavras, frases ou ideias que ocorreram com mais frequência dentro de cada categoria. Significados semelhantes foram agrupados.

\begin{tabular}{|c|c|c|c|}
\hline TIPO DE PÚBLICO & TIPO DE RELACIONA-MENTO & OBJETIVO DO CONGRESSO & \begin{tabular}{|l|} 
EXPECTA-TIVAS DO PÚBLICO \\
\end{tabular} \\
\hline $\begin{array}{l}\text { Turistas e visitantes sem } \\
\text { agendamento prévio }\end{array}$ & Social & $\begin{array}{c}\text { Despertar o interesse e } \\
\text { a percepção do visitante } \\
\text { sobre o Poder Legislativo, } \\
\text { representação e participação. } \\
\text { Apresentar o patrimônio } \\
\text { público. }\end{array}$ & $\begin{array}{c}\text { Ter o status de ter visitado. } \\
\text { Conhecer o patrimônio } \\
\text { público, fazer passeio turístico. } \\
\text { Fotografar. }\end{array}$ \\
\hline Estudantes & Social & $\begin{array}{l}\text { Mostrar o funcionamento do } \\
\text { Congresso Nacional. } \\
\text { Contar parte da história da } \\
\text { Casa e do País. } \\
\text { Despertar o interesse e a } \\
\text { percepção do visitante sobre } \\
\text { representação/participação. }\end{array}$ & $\begin{array}{c}\text { Entender associações } \\
\text { feitas em sala de aula ao } \\
\text { funcionamento na prática das } \\
\text { atividades legislativas. } \\
\text { Entender o papel dele como } \\
\text { cidadão em relação às } \\
\text { atividades legislativas. } \\
\text { Muitas vezes, a expectativa é } \\
\text { do professor e não do aluno. }\end{array}$ \\
\hline Professores & $\begin{array}{c}\text { Social } \\
\text { Parcerias }\end{array}$ & $\begin{array}{c}\text { Servir de apoio aos conteúdos } \\
\text { didáticos ensinados em sala } \\
\text { de aula. }\end{array}$ & $\begin{array}{c}\text { Receber mais informações } \\
\text { para serem repassadas em } \\
\text { sala de aula. } \\
\text { Ter uma experiência cívica } \\
\text { com seus alunos. }\end{array}$ \\
\hline Profissionais & $\begin{array}{c}\text { Social } \\
\text { Parcerias }\end{array}$ & $\begin{array}{l}\text { Mostrar o funcionamento do } \\
\text { Congresso Nacional. Fornecer } \\
\text { informação qualificada de } \\
\text { áreas específicas, como } \\
\text { Direito, Arquitetura e História. }\end{array}$ & $\begin{array}{l}\text { Conseguir associar suas } \\
\text { profissões às atividades do } \\
\text { Congresso Nacional. } \\
\text { Aprofundar o conhecimento } \\
\text { de sua área de interesse. }\end{array}$ \\
\hline
\end{tabular}




\begin{tabular}{|c|c|c|c|}
\hline TIPO DE PÚBLICO & TIPO DE RELACIONA-MENTO & OBJETIVO DO CONGRESSO & EXPECTA-TIVAS DO PÚBLICO \\
\hline Estrangeiros & Social & $\begin{array}{c}\text { Apresentar as duas } \\
\text { instituições brasileiras } \\
\text { como pilares da sociedade } \\
\text { democrática. } \\
\text { Apresentar o patrimônio } \\
\text { brasileiro. }\end{array}$ & $\begin{array}{l}\text { Experiência turística, } \\
\text { curiosidade pela cultura e } \\
\text { estrutura de governo do País. }\end{array}$ \\
\hline 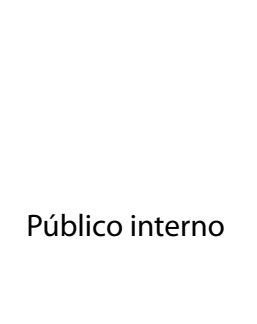 & Social & $\begin{array}{l}\text { Mostrar aos familiares e } \\
\text { amigos dos servidores onde } \\
\text { estes trabalham. } \\
\text { Melhorar a ambientação no } \\
\text { caso de novos servidores. }\end{array}$ & $\begin{array}{l}\text { Conhecer o ambiente de } \\
\text { trabalho do familiar servidor. } \\
\text { Poder conhecer melhor o seu } \\
\text { ambiente de trabalho. }\end{array}$ \\
\hline
\end{tabular}

Fonte: Diagnóstico de comunicação do programa de visitação do Senado Federal - Arquivo eletrônico da Secretaria de Relações Públicas do Senado Federal.

O razoável número de mensagens em branco, ilegíveis ou as que apenas registraram a presença de visitantes, $9 \%$ do total, pode ser interpretado como um indicativo de que um em cada dez visitantes não compreendeu a finalidade do livro, quer seja pela falta de mais informações, quer seja pelo leiaute do formulário.

Do total de manifestações, 741 delas, ou seja, $61 \%$, qualificam a visita como de grande proveito, com destaque para as que citam os mediadores como responsáveis pela boa experiência que tiveram no Congresso Nacional. Com frequência, os turistas elogiam a cidade de Brasília, exaltando sua originalidade e qualidades.

Gráfico 1- ELOGIOS E AGRADECIMENTOS, de 16/04/2010 a $20 / 04 / 2011$

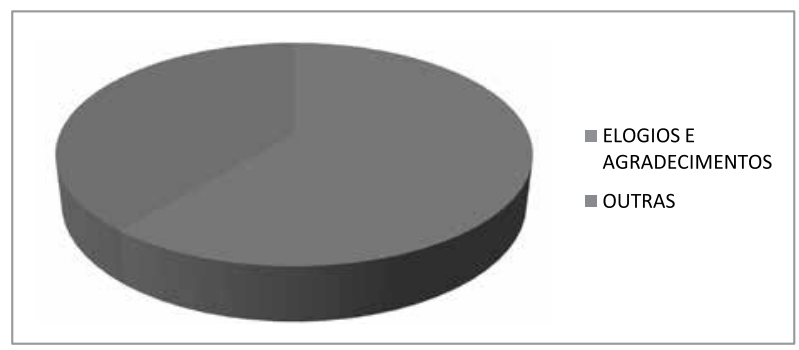

Fonte: próprio autor

A lista de manifestações elogiosas e agradecimentos mais comuns é a seguinte:

a) Visita: esclarecedora, surpreendente, instrutiva, proveitosa, didática, elucidativa, emocionante, enriquecedora, ilustrativa, importante, prazerosa;

b) Mediadores: educados, prestativos, atenciosos, conhecedores, pacientes;

c) Brasília;

d) Arquitetura e obras de arte no Congresso;

e) Agradecimentos: recepção, acesso livre;

f) Democracia, abertura;

g) Visite Encena (projeto de visitação com a intervenção de atores caracterizados de personagens históricos);

h) Orgulho/civismo/patriotismo/cidadania.

Quanto à categoria solicitações, com 200 manifestações (16\% do total), um dos destaques é o pedido de catálogos das exposições de arte organizadas pela Câmara dos Deputados em suas dependências.

Gráfico 2 - SOLICITAÇÕES, de 16/04/2010 a 20/04/2011

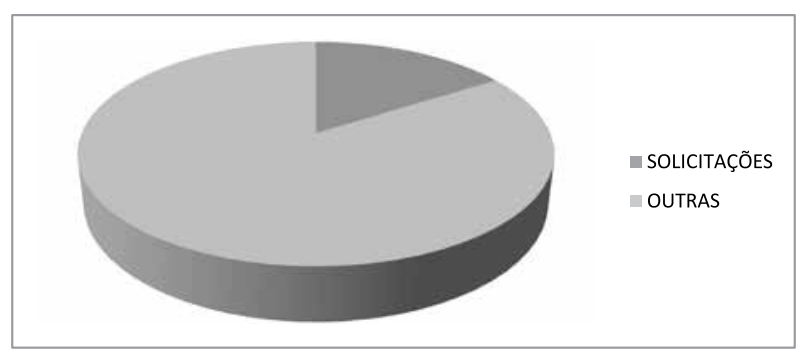

Fonte: próprio autor 
Considerável é o número de mensagens que pede mais trabalho e dedicação dos parlamentares para resolver os problemas da população. Alguns visitantes utilizam o livro para se manifestarem sobre problemas locais em suas comunidades, como segurança pública e saúde. Outros solicitam atenção de senadores e deputados para diversos tipos de projetos de lei e para os mais variados temas de interesse público.

Especificamente sobre o Programa de Visitas, alguns cidadãos pedem materiais informativos sobre o conteúdo do roteiro. A lista de solicitações mais comum é a que segue:

a) Catálogos de exposições;

b) Dedicação dos parlamentares;

c) Demandas locais;

d) Legislação: aprovação de projetos de lei: PEC 300, Ficha Limpa, Meio Ambiente, Fator Previdenciário, reforma tributária, entidades de classe, saúde, educação;

e) Informativo sobre o conteúdo da visita.

Juntas, as 93 críticas registradas no período pesquisado perfazem $8 \%$ do total de manifestações. O tema que aparece com mais frequência diz respeito aos problemas de acessibilidade no Congresso Nacional. Outras duas queixas comuns são sobre os mediadores e a ausência de parlamentares, principalmente nos plenários das duas Casas:

a) Acessibilidade: estacionamentos, elevadores, rampas;

b) Mediadores: rudes, ignorantes, indiferentes, fala mal o Português, fala muito rápido, superficial, cansativo;

c) Ausência/pouco trabalho de parlamentares;

d) Pouco tempo de visita;

e) Mau atendimento: policiais, vigilantes;

f) Organização ruim;

g) Proibição de entrada usando shorts ou bermudas;

h) Ar condicionado desligado; i) Roteiro: espaços fechados (por ocasião de obras de manutenção ou por motivo de segurança);

j) Site complicado e informações obtidas por telefone erradas.

Gráfico 3 - CRÍTICAS, de 16/04/2010 a 20/04/2011

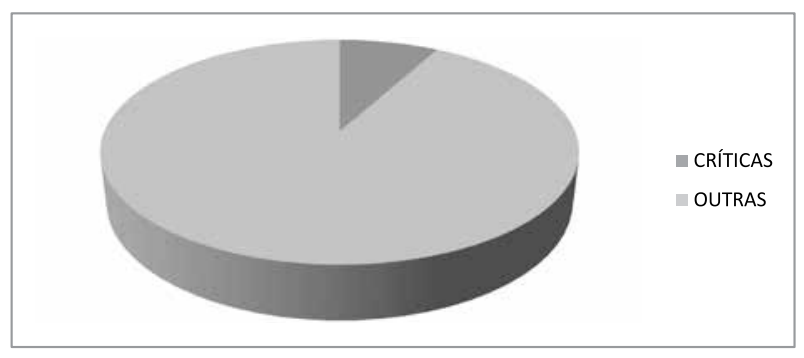

Fonte: próprio autor

Do total, 6\% (71 manifestações) foram de sugestões.

Gráfico 4 - SUGESTÕES, de 16/04/2010 a 20/04/2011

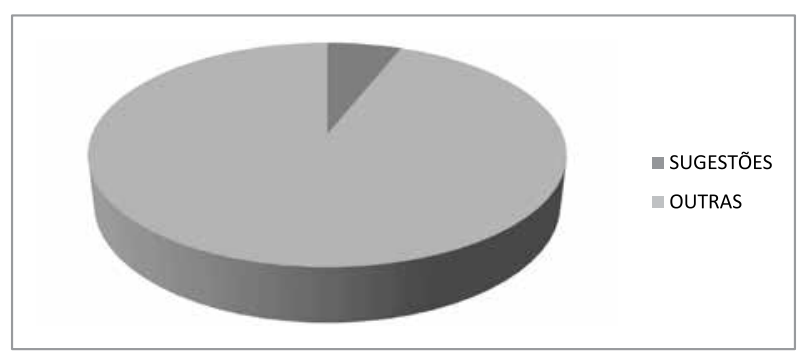

Fonte: próprio autor

Entre as mais comuns estão as que tratam da manutenção e conservação do prédio. Muitos também expressam o desejo de que todos os brasileiros tivessem a oportunidade de conhecer o Congresso Nacional. O vídeo institucional também foi alvo de várias sugestões de melhoria:

a) Restaurar o prédio: placas de alumínio do plenário do Senado, banheiros, carpetes;

b) Participação da sociedade: todos deveriam vir;

c) Vídeo institucional: atualização, tela maior, disponibilizar em DVD, legendas em Inglês, legendas para pessoas com deficiência auditiva;

d) Visitas ampliadas: visita a outros anexos da Câmara e do Senado; 
e) Melhor divulgação de horários;

f) Melhorar sinalização;

g) Visite Encena para datas comemorativas;

h) Horário especial de visita em Inglês - audioguias em outros idiomas;

i) Entrega de certificado para estudantes;

j) Material institucional em Braille.

\subsubsection{As respostas do Congresso Nacional}

Desde a implantação do livro Palavra do Visitante, a equipe de visitação da Secretaria de Relações Públicas do Senado Federal tem respondido a cada mensagem registrada pelo cidadão que deixa alguma forma de contato.

As mensagens que contêm elogios recebem uma resposta padrão de agradecimento, que convida o cidadão a acessar as páginas de internet do Senado Federal e da Câmara dos Deputados.

As críticas, sugestões e solicitações são respondidas de forma customizada. Quando cabível, a informação contida na mensagem é verificada e encaminhada para providências. A orientação para as respostas é a de reconhecer o problema existente, esclarecer sobre a questão levantada e fornecer explicações, além de informar sobre que tipo de providência foi ou será tomada. Quando a mensagem é direcionada a algum parlamentar específico, o serviço "Alô Senado", que registra as mensagens do Palavra do Visitante em seu sistema, as encaminha diretamente àquele senador.

Se a mensagem é genérica ao se referir aos senadores, o cidadão é informado sobre como entrar em contato com os parlamentares de seu estado ou de sua preferência.

A maioria das respostas do Congresso às mensagens dos visitantes é feita por e-mail. Não raro o cidadão responde expressando surpresa por ter sido respondido e agradecendo pela atenção dispensada.

\subsubsection{Discussão de resultados e mudanças obtidas a partir do tratamento das críticas e sugestões dos visitantes}

A análise das palavras desse pouco mais de um milhar de visitantes foi útil como termômetro das opiniões dos cidadãos que adentram o Parlamento brasileiro. Além disso, poderá ser usada pelos setores de Relações Públicas do Congresso como subsídio para ajustar o Pro- grama de Visitas às expectativas dos públicos visitantes. Assim, no âmbito desse Programa, será possível posicionar o cidadão de simples receptor a interlocutor, como preconiza Oliveira (2011, p. 80).

As respostas enviadas pelo Congresso Nacional aos cidadãos são uma busca pelo diálogo, tão necessário no processo de comunicação pública. O encaminhamento das mensagens bem como o atendimento de diversas demandas dos visitantes demonstram como a contribuição dos visitantes é útil para o aperfeiçoamento do Programa Visite o Congresso, bem como das próprias instituições do Legislativo brasileiro. Abre espaço também para que os resultados almejados por Grunig (2009, p. 91) sejam alcançados no relacionamento entre instituição e públicos: percepção mútua, exatidão, compreensão, concordância e comportamento simbiótico.

Entretanto, o alcance do livro "Palavra do Visitante" necessita ser ampliado, talvez com uma versão eletrônica, com formulário a ser preenchido em totens eletrônicos e sistema que classifique e contabilize as mensagens dos visitantes, cujo número tende a aumentar nos próximos anos.

Ainda assim, as mensagens devem continuar sendo respondidas com atenção e respeito ao cidadão, de forma personalizada, de acordo com o modelo de comunicação direta explicado por Duarte (2009, p. 66). As sugestões e críticas de um número maior de visitantes podem contribuir ainda mais para o aperfeiçoamento do Programa de Visitas do Congresso Nacional e do fortalecimento do Senado Federal e da Câmara dos Deputados como instituições democráticas e fundamentais para País.

Como destaque, embora não seja uma surpresa, a expectativa dos cidadãos em ver mais dedicação e trabalho por parte dos parlamentares surgiu claramente em muitas manifestações do Palavra do Visitante. Essa constatação coincide com as pesquisas de Meneguello (2012, p. 13) sobre as impressões gerais da sociedade sobre os parlamentares.

Pela reflexão proporcionada tanto pela revisão bibliográfica sobre comunicação pública, relações públicas e mensuração de resultados, quanto pelo caso particular do diálogo proporcionado entre cidadãos e o Parlamento brasileiro por meio do Programa Visite o Congresso, foi possível perceber alguns princípios para se obter bons resultados de relações públicas no contexto das organi- 
zações públicas. De maneira alguma se pretendem definitivos, carecendo de mais pesquisas que poderão ser conduzidas futuramente em outras instituições públicas. São eles:

a) A área e/ou os profissionais de relações públicas devem compreender em profundidade a missão, o propósito e os objetivos da organização pública, sem perder de vista a função de vinculação com os stakeholders, como orienta Grunig (2009, p. 41);

b) Os cidadãos são interlocutores, não receptores passivos. Essa máxima é defendida por grande parte dos autores pesquisados, como Oliveira (2011, p. 80) e Jorge Duarte (2009, p. 61);

c) Os dirigentes de relações públicas devem fazer parte da tomada de decisão da organização. Tal afirmação é encontrada nos estudos de Grunig (2009, p. 41);

d) Os esforços de relações públicas fazem sentido se inseridos em um planejamento, com objetivos e metas bem definidos. Os modelos de avaliação e mensuração de resultados, como o Modelo PII, a Régua da Efetividade e Balanced score card, descritos por Galerani (2006, p. 72), atestam esse princípio;

e) Os objetivos de qualquer programa ou ação de relações públicas devem contribuir para a eficácia da organização pública dentro da perspectiva do interesse público. É o que perceberam os servidores da Câmara dos Deputados ao pesquisar sobre o trabalho de comunicação pública daquela instituição (BARROS et al., 2008, p. 44);

f) As relações públicas no contexto governamental devem tomar a iniciativa de orientar seus públicos sobre onde encontrar as informações necessárias para que aumentem seus conhecimentos e capacidade de participar e agir de forma cidadã. Este fundamento encontra ressonância no trabalho de Torquato (2011, p. 128), que descreve como funções da comunicação pública a democratização do poder e a orientação aos cidadãos;

g) Defendidas por Zémor (2009, p. 220), a recepção, a escuta e o diálogo são regras dos programas de relações públicas;

h) Um projeto de relações públicas necessita ser avaliado em todas as etapas, não apenas em sua conclusão. É o que se pode inferir pelos métodos de avaliação descritos por Lopes (2009, p. 395);

i) Cada projeto ou programa de relações públicas se adéqua a um instrumento de medição diferente. A pesquisa de opinião é uma ferramenta importante e talvez a mais comum, embora não seja a única. No caso do Programa de Visitas do Congresso, foi utilizado o método de análise de conteúdo, definido por Stacks (2007, p. 14).

Esses princípios evidenciam que a escuta e o diálogo entre instituição pública e os cidadãos é uma necessidade inequívoca. Nessa perspectiva, os cidadãos se transformam em co-autores dos serviços públicos.

A relação entre comunicação pública e construção da cidadania pode ser interpretada como reflexo da organização política das sociedades cujas bases democráticas permitem que as vozes dos cidadãos encontrem ressonância junto às instituições.

Vale ressaltar que a cidadania parece ser tratada pelos autores citados neste artigo como uma conquista, um estado evolutivo ainda não consolidado, que precisa ser construído e para o qual a comunicação pública pode contribuir. Essa construção exige esforço para que se encontre um terreno comum de entendimento e cooperação mútua entre as instituições públicas e os cidadãos.

Entre 2010 e 2012, várias críticas e sugestões de visitantes foram consideradas pelo Programa Visite o Congresso. Melhorias e ajustes foram incorporados à visitação. Mensagens relacionadas a outras áreas do Senado ou da Câmara foram encaminhadas aos respectivos setores responsáveis que se encarregaram dos assuntos em questão.

O treinamento dos mediadores da visitação passou a ser uma preocupação constante. As mensagens relacionadas à acessibilidade foram encaminhadas ao Serviço 
de Acessibilidade do Senado que incorporou várias ideias ao seu plano de ação. Os materiais institucionais foram vertidos para o Braille e membros da equipe de acessibilidade foram deslocados para o Salão Negro em caráter permanente para auxiliar pessoas com dificuldades de locomoção.

O vídeo institucional ganhou legenda em Inglês, e materiais institucionais com as principais informações sobre a visitação foram traduzidos para outros idiomas.

Os registros sobre a manutenção e reforma de espaços foram enviados aos setores de Engenharia. Algumas dessas reformas já constavam do calendário de obras das duas Casas, mas as mensagens dos visitantes reforçaram ainda mais a necessidade de manutenção.

No roteiro da visitação, foi incluído esclarecimento sobre a ausência ou presença de parlamentares nos Plenários, uma vez que o trabalho dos deputados e senadores não se restringe a esses espaços, sendo realizado, em boa parte, nas reuniões das comissões permanentes e temporárias, nas audiências públicas e nos gabinetes. Sobretudo, obtiveram maior destaque no roteiro as formas de participação e acesso à informação disponível aos cidadãos.

\section{Considerações finais}

De acordo com o objetivo proposto inicialmente, o presente artigo identificou e descreveu informações sobre a qualidade do Programa Visite o Congresso e percepções dos cidadãos participantes da visita mediada, a partir da análise de conteúdo das manifestações registradas no livro Palavra do Visitante.

A possibilidade de manifestação dada aos visitantes e as respostas enviadas pela Câmara e pelo Senado são representações materiais de uma conversa cada vez mais necessária entre as Instituições legislativas e seus públicos, motivada pela visitação ao Palácio do Congresso Nacional.

Uma medição qualitativa dos resultados do Programa Visite o Congresso foi executada por meio da análise de conteúdo das mensagens registradas no livro Palavra do Visitante. A partir dela, foi possível responder às perguntas originais deste artigo. Os dados s sapontam que o Programa Visite o Congresso é visto pela maioria dos participantes como didático e importante, aumentando a compreensão a respeito do Poder Legislativo. Também revela que os mediadores da visitação exercem um papel fundamental para a satisfação dos visitantes. Ainda há, porém, muito a avançar nas questões de acessibilidade do Palácio, na disponibilização de informações sobre o processo legislativo, na organização geral do Programa, e no aproveitamento do tempo da visita, para que se torne ainda mais instrutiva e esclarecedora.

Medir e demonstrar resultados em relações públicas tem sido uma preocupação crescente entre profissionais da área. São demandas das instituições e empresas, especialmente as que compreendem a potencialidade estratégica da contribuição das relações públicas para a eficácia organizacional.

Reunir, interpretar e sintetizar o que há de mais relevante no campo da mensuração de resultados são tarefas árduas, especialmente em se tratando da perspectiva de instituição pública de governo, já que os exemplos mais comuns de mensuração de resultados vêm da área privada. Consiste em desafio aos que têm como objeto de estudo as relações públicas no setor público desenvolver sistemas eficazes de mensuração de resultados.

O Mundo mudou intensamente nos últimos 20 anos em praticamente todas as esferas, especialmente na área da tecnologia e velocidade da informação. Nesse período, o Brasil passou por transformações profundas nos campos político, econômico, cultural e social. O Congresso Nacional, como instituição de Poder e representação política, ora foi agente de mudanças, ora se adaptou a elas, em resposta a novas demandas sociais. Ora foi espelho das contradições do País, ora contradisse as expectativas de seus representados.

Ao abrirem suas portas para a visitação pública, o Senado Federal e a Câmara dos Deputados dão aos cidadãos que os visitam a chance de se apropriarem dos conceitos arquitetônicos impressos em suas estruturas e espaços, do patrimônio público, da história brasileira e, tomara, da dimensão de sua responsabilidade em contribuir para aperfeiçoá-los continuamente a fim de que representem digna e incansavelmente o interesse público. 


\section{Referências}

BARROS, Antonio Teixeira et al. Avanços e desafios do sistema de comunicação da Câmara dos Deputados. In: MESSENBERG, Débora et al. (Org.) Estudos legislativos: pensamento e ação política. Brasília: Câmara dos Deputados, Coordenação de Publicações, 2008. p. 31-54.

BRANDÃO, Elizabeth Pazito. Conceito de comunicação pública. In: DUARTE, Jorge (Org.). Comunicação pública: estado, mercado, sociedade e interesse público. 2. ed. São Paulo: Atlas, 2009. p. 1-33.

DUARTE, Jorge. Instrumentos de comunicação pública. In: DUARTE, Jorge (Org.). Comunicação pública: estado, mercado, sociedade e interesse público. 2. ed. São Paulo: Atlas, 2009. p. 59-71.

DUARTE, Márcia Yukiko Matsuuchi. Central de atendimento 0800 do Senado Federal: uma história de conquistas para o cidadão. In: MOURA, Cláudia Peixoto (Org.). História das relações públicas: fragmentos da memória de uma área. Porto Alegre: EdiPUCRS, 2008. p. 319-340.

DUARTE, Márcia Yukiko Matsuuchi. Comunicação e cidadania. In: DUARTE, Jorge (Org.). Comunicação pública: estado, mercado, sociedade e interesse público. 2 . ed. São Paulo: Atlas, 2009. p. 95-115.

FRANÇA, Fábio. Públicos: como identificá-los em uma nova visão estratégica: business relationship. 2. ed. São Caetano do Sul: Yendis, 2008.

GALERANI, Gilceana Soares Moreira. Avaliação em comunicação organizacional. Brasília: Embrapa, 2006.

GRUNIG, James; FERRARI, Maria Aparecida; FRANÇA, Fábio. Relações públicas: teoria, contexto e relacionamentos. São Caetano do Sul: Difusão, 2009.

LOPES, Valéria de Siqueira Castro; GRANDI, Guilherme. Avaliação, mensuração e valoração em relações públicas. In: KUNSCH, Margarida M. Krohling (Org.) Relações públicas: história, teorias e estratégias nas organizações contemporâneas. São Paulo: Saraiva, 2009. p. 391-414

MATOS, Heloiza. Comunicação pública, esfera pública e capital social. In: DUARTE, Jorge (Org.). Comunicação pública: estado, mercado, sociedade e interesse público. 2. ed. São Paulo: Atlas, 2009. p. 47- 58.
MENEGUELLO, Rachel. Percepções públicas sobre o Parlamento brasileiro: dados dos últimos 50 anos. In: MENEGUELLO, Rachel (Org.). O legislativo brasileiro: funcionamento, composição e opinião. Brasília: Senado Federal, Secretaria Especial de Comunicação Social, 2012. p. 13 a 34.

OLIVEIRA, Maria José da Costa. De públicos para cidadãos: uma reflexão sobre relacionamentos estratégicos. In: FARIAS, Luiz Alberto de (Org.). Relações públicas estratégicas: técnicas, conceitos e instrumentos. São Paulo: Summus, 2011.

SANTOS, Marco Antonio Pereira dos. Conceito de BSC. Portal Educação. 2008. Disponível em: <http://www. portaleducacao.com.br/gestao-e-lideranca/artigos/3949/ o-que-e-balanced-scorecard>. Acesso em: 26 jan. 2013.

SENADO FEDERAL. Notícias/DataSenado/Institucional. Brasília, 2012. Disponível em: <http://www.senado.gov. $\mathrm{br} /$ noticias/datasenado/ institucional.asp $>$. Acesso em: 27 nov. 2012.

SENADO FEDERAL. Secretaria de Relações Públicas. Diagnóstico de comunicação - programa de visitação do Senado Federal. Brasília, 2011. Arquivo da Secretaria de Relações Públicas do Senado Federal. Trabalho não publicado.

SENADO FEDERAL. Secretaria de Relações Públicas. Livro Palavra do Visitante. Brasília: SEEP - Gráfica do Senado, 2010. 3 v.

STACKS, Don W. Dicionário de mensuração e pesquisa em relações públicas e comunicação organizacional. São Paulo: Aberje, 2007.

TORQUATO, Gaudêncio. Tratado de comunicação organizacional e política. 2. ed. revista e ampliada. São Paulo: Cengage Learning, 2011.

ZÉMOR, Pierre. As formas da comunicação pública. In: DUARTE, Jorge (Org.). Comunicação pública: estado, mercado, sociedade e interesse público. 2. ed. São Paulo: Atlas, 2009. p. 214-245. 
Para publicar na revista Universitas: Arquitetura e Comunicação Social, acesse 0 endereço eletrônico www.publicacoesacademicas.uniceub.br. Observe as normas de publicação, para facilitar e agilizar o trabalho de edição. 